\title{
La familia como promotora de la independencia en niños y niñas con discapacidad motora
}

\section{Family as the Promoter of Independence Skills in Children with Motor Disabilities}

\author{
María Roxana Rodríguez Araya \\ División de Educación Básica, Centro de Investigación y Docencia en Educación \\ Universidad Nacional \\ Heredia, Costa Rica \\ rodri156@gmail.com \\ Carolina Guerrero Castro ${ }^{2}$ \\ Centro de Enseñanza Especial de Heredia \\ Ministerio de Educación Pública \\ Heredia, Costa Rica \\ akyfel@gmail.com
}

Recibido 10 de noviembre de 2011 • Aceptado 23 de febrero 2012

\begin{abstract}
Resumen. En el estudio se desarrolló una propuesta individualizada para promover desde el contexto familiar el desarrollo de la independencia en dos niños de cuatro años con discapacidad motora. La propuesta tiene como meta apoyar a la familia para que esta promueva destrezas en los niños y las niñas dentro del contexto familiar. Los resultados de este estudio muestran que cuando existe una guía para las familias de personas con discapacidad es más sencillo para estas iniciar procesos que de otra forma podrían verse pospuestos. A raíz de los resultados se recomienda crear propuestas de apoyo para padres y madres que les permitan construir sus propios procesos de crecimiento familiar y de desarrollo de la independencia en sus niños o niñas con discapacidad motora.
\end{abstract}

Palabras claves. Familia, independencia, apoyo.

Abstract. This study developed an individualized proposal to promote, from the family context, the independence of two four-year-old children with motor disabilities. The proposal aimed at helping mothers and fathers to promote different skills within the family context. The results of this study revealed that when the families of children with disabilities are oriented, it is easier for them to start processes that otherwise would be postponed. As a result, it is recommended to create proposals to support the parents and help them to build their own family-growth processes and develop independence living skills in their children with motor disabilities.

Keywords. Family, independence, support.

Maestría Académica de la Universidad de Minnesota, certificado en Desórdenes del Espectro Autista de la Universidad de Minnesota. Bachiller en Educación Preescolar de la Universidad Estatal a Distancia de Costa Rica. Laboró como investigadora asociada en HACER (Hispanic Advocacy and Community Empowerment through Research) y centros educativos dentro y fuera del país. Actualmente labora como académica en la Universidad Nacional, en la División de Educación Básica y en el Proyecto UNA Educación de Calidad.

2 Licenciada en Educación Especial con énfasis en Integración de la Universidad Nacional de Costa Rica. Bachiller en Educación Especial con énfasis en Integración de la Universidad Nacional de Costa Rica. Ha trabado durante cuatro años como docente Itinerante en el Servicio de Discapacidad Cognitiva del Centro de Enseñanza Especial de Heredia (CEEH) del Ministerio de Educación Pública de Costa Rica (MEP), lugar donde labora actualmente. 


\section{Introducción}

La investigación se motiva en la necesidad, observada en la práctica docente, de apoyo requerido por los padres y madres de niños y niñas con discapacidad motora, así como en el reconocimiento de la importancia de promover mayores oportunidades de independencia en esta población, de manera que se favorezca su crecimiento como seres integrales.

Durante el desarrollo del estudio se evidenció que existen desafíos sistémicos en la atención de las necesidades de estas familias, así como desafíos a lo interno de los núcleos familiares para promover el desarrollo de la independencia de los niños y niñas con discapacidad. Estos desafíos son multidimensionales: involucran aspectos sociales, educativos, económicos, conyugales, de valores, roles familiares y hasta de expectativas relacionadas con las capacidades de desarrollo de la persona con discapacidad.

La reflexión se centra en el papel que tiene la familia en el desarrollo de la independencia del niño con discapacidad motora y reconoce la necesidad de proporcionar apoyos específicos a las familias por parte de profesionales que pueden guiar los procesos evolutivos a lo interno del núcleo. Asimismo, se ofrecen algunas pautas de acción que medien la perspectiva sistémica de promoción de la familia como formadora del individuo, a una visión que reconoce la necesidad de proveer a las familias de instrumentos para promover destrezas en los niños y las niñas con discapacidad, los cuales permitan formar personas más independientes y responsables de sus acciones.

\section{Marco teórico}

De acuerdo con la (Guía para la atención educativa a los alumnos y alumnas con discapacidad motora, s. f.), el movimiento se produce por la percepción de un estímulo interno o externo; el estímulo se recibe, codifica y procesa por el sistema nervioso central, y luego se elabora una respuesta. La discapacidad motora se presenta cuando alguno de los pasos mencionados -que forman el proceso motor-, sufre una alteración o está ausente. Por tanto, se deduce que la discapacidad motora es la alteración orgánica del aparato motor que puede afectar el sistema óseo, articulatorio, nervioso o muscular (Peñafiel, 1998); además, al presentar esta condición, existe una desventaja locomotora e incluso otras alteraciones vinculadas como sensoriales, perceptivas o de lenguaje. Entre sus características, la discapacidad motora puede incluir espasmos o rigidez en los músculos, movimientos involuntarios, o trastornos en la postura o movilidad del cuerpo. Las personas que presentan una lesión cerebral no progresiva se caracterizan por presentar parálisis, debilidad, descoordinación u otras alteraciones de la función motora (Póo, 2008). Con base en lo anterior, se define la discapacidad motora como un grupo de síndromes ocasionados por una lesión cerebral de tipo irreversible, no progresivo, que se produce durante la gestación, en el momento del parto o en el periodo postnatal.

Por consiguiente, para desarrollar destrezas de movilidad, cognitivas, de lenguaje y sociales, las personas con discapacidad motora requieren una serie de apoyos a nivel médico, social, familiar y educativo. El grado requerido de colaboración varía de acuerdo con las características de la discapacidad que presente el sujeto como resultado de la lesión, así como de la estimulación social y familiar disponible. 


\section{La familia ante la discapacidad}

El término discapacidad se entiende en la Convención sobre los derechos de las personas con discapacidad, en el preámbuo e) como uno que “(...) evoluciona y que resulta de la interacción entre las personas con deficiencias y las barreras debidas a la actitud y al entorno que evitan su participación plena y efectiva en la sociedad, en igualdad de condiciones con las demás" (ONU, 2006, p.1). En el marco de la nueva interpretación que ofrece la convención de la definición de discapacidad, se evidencia que las barreras del entorno responden, en muchas ocasiones, a las percepciones del contexto sobre la discapacidad. Sin embargo, más allá de enfocar las barreras, el documento de la convención invita a promover espacios sociales inclusivos que permitan que estas barreras sean eliminadas o disminuidas; uno de estos espacios es el contexto familiar en el que se desenvuelven los individuos.

La eliminación o disminución de las barreras sociales que enfrentan las personas con discapacidad debe iniciar en el hogar: es la familia el primer ente social que forma de acuerdo con sus concepciones sobre la discapacidad. La manera en la que la familia aborde el tema marcará muy particularmente el desarrollo social de la persona. En esta línea, Fishman, citado por Campabadal (2007), menciona que mientras mejor estructurada sea la relación familiar y las interrelaciones que en ella se den en aspectos emocionales, cooperativos, de comunicación y resolución de conflictos, el pronóstico de ajuste a las nuevas demandas que surgen a raíz de la discapacidad serán más positivas para los sujetos que la componen.

Se hace evidente, a la luz del enfoque social de la discapacidad, que la perspectiva de la educación sobre la familia se ha ido transformando, y se ha iniciado un proceso de concienciación sobre su rol fundamental en el desarrollo del individuo. Según Fantova (2000), es en la familia donde se suplen necesidades sociales de los miembros que la conforman; por esto, el trabajo desarrollado en el núcleo debe partir del análisis desde la familia y para ella, de allí que su participación sea tan importante durante el proceso y como un fin social. Este proceso organiza y refuerza los recursos y los procesos que vive la familia como ente de la sociedad.

Es así como la familia se identifica como clave para el desarrollo del individuo en todas sus dimensiones. Cuando se reconoce este hecho, se evidencia que no existe otra ruta más que procurar la participación activa y efectiva de la familia en cualquier proceso personal o social de las personas; particularmente cuando uno de sus miembros posee una condición de discapacidad.

\section{La familia como promotora en la adquisición de habilidades de la vida personal (habilidades adaptativas) y de independencia}

El rol de la familia resulta de suma importancia en la adquisición de habilidades para la vida. Para fines del estudio, la conducta adaptativa se refiere al conjunto de habilidades tanto conceptuales, como sociales y prácticas que los individuos aprenden para desempeñarse adecuadamente en su vida cotidiana (Asociación Americana sobre Retardo Mental [AAMR], 2004).

Tradicionalmente, se ha comprendido que la adquisición de habilidades adaptativas se da en el seno de la educación institucionalizada y se ha considerado al docente en educación especial como el único promotor en la adquisición de estas destrezas. Sin embargo, gradualmente se ha incitado sobre la importancia de desarrollar estas destrezas en el hogar, siempre contando con el apoyo de profesionales en la materia que favorezcan los procesos a seguir. 
El desarrollo de habilidades adaptativas en el individuo con discapacidad tiene como meta lograr la independencia en los diferentes ámbitos en los que se pueda desarrollar. En las familias de niños y niñas con discapacidad, es común identificar sentimientos de sobreprotección por parte de los demás miembros. En algunas ocasiones se considera que los menores y las menores no poseen la capacidad para realizar una actividad específica, se desea evitar que se hagan daño, o incluso obtener un resultado más rápido al pedirles que ejecuten alguna acción. Estas actitudes y prácticas cotidianas comúnmente observadas en el seno de las familias con niños y niñas con alguna discapacidad motora no favorecen el desarrollo de su independencia, debido a que estas habilidades se adquieren y desarrollan a través de pequeñas y sencillas actividades que acontecen primordialmente en el hogar.

\section{Apoyo a la familia en la promoción de la independencia de niños y niñas con discapacidad}

En el contexto de este estudio se considera la palabra apoyo como la atención continua que relaciona la evolución de la persona con discapacidad y su familia, con el propósito de promover respuestas específicas a las necesidades que surgen en los diferentes períodos del ciclo de vida. Este apoyo se concibe como un trabajo interdisciplinario, integral y especializado.

a. Trabajo interdisciplinario: se evidencia la necesidad de contar con especialistas en áreas como lenguaje, terapia física, educación, entre otros.

b. Trabajo integral: se consideran todas las dimensiones de desarrollo de la persona y la realidad familiar en la que vive el individuo con discapacidad motora.

c. Trabajo especializado: el eje central debe ser la familia, es esencial que equipos profesionales puedan ayudar a iniciar procesos de independencia que se transfieran, desde el hogar, hacia la escuela y la comunidad.

Una visión adecuada de apoyo es necesaria en el trabajo desarrollado en busca de laindependencia de las personas con discapacidad motora; ya que los padres y madres generalmente manejan poca información con respecto a la condición de sus hijos o hijas. Además, si a esto se le añaden las diferentes etapas del proceso de duelo que usualmente se presentan durante la aceptación de una persona con discapacidad en el núcleo familiar, resulta en muchos casos una mayor vulnerabilidad de parte del miembro de la familia que presenta la condición de discapacidad (Campabadal, 2007).

Por el contrario, cuando la familia se visualiza como un experto en la realidad y en la cotidianidad de la persona con discapacidad, se pueden promover acciones de apoyo específicas que conlleven al desarrollo de habilidades adaptativas de estas personas y, consecuentemente, su independencia.

La familia conoce mejor las características de los niños y las niñas y tiene mayor interés en su desarrollo. Según (Giangreco, Clininger e Iverson, citados por Heward, 1997, p. 508 y estos citados a su vez por Fontana et al., 2009), “(...) es muy probable que la familia sea el único grupo que va a intervenir en la educación del niño y la niña a lo largo de toda su educación (...)” (p. 22). Las familias pueden influir positivamente en la calidad de los servicios educativos, pues son ellas mismas las que viven con los resultados de las decisiones tomadas por los equipos educativos; a pesar de esto, en ocasiones no son tomadas en cuenta sobre las decisiones que se deben tomar al trabajar con los menores y las menores. Por lo tanto, se considera que los procesos de apoyo al individuo, así como 
las intervenciones, deben darse en coordinación cercana con la familia, reconociendo su importancia en el desenvolvimiento del individuo con discapacidad. Se espera que en la medida que se responda a las características y a las necesidades del individuo, mayor será la posibilidad de comprender y ubicar las ofertas adecuadas de atención en cada ambiente.

\section{El quehacer metodológico}

El estudio se desarrolló en el paradigma cualitativo y en el tipo de estudio investigación acción. El objetivo principal de este estudio fue explorar los apoyos que requieren los padres y madres de los menores con discapacidad para potenciar su independencia en la cotidianidad del hogar. Los participantes de la investigación fueron dos niños de cuatro años con discapacidad motora y sus familias.

Para lograr el objetivo, se realizó una evaluación de las habilidades adaptativas de los niños utilizando el CALS (Checklist of Adaptive Living Skills). El CALS es una de tres herramientas que constituyen el Sistema de Valoración-Enseñanza-Evaluación, creado en Estados Unidos por Morreau y Bruininks. Este instrumento se divide en cuatro áreas (destrezas de la vida personal, destrezas de la vida en el hogar, destrezas de la vida en comunidad y destrezas laborales), que a su vez se subdividen en veinticuatro sub áreas con un nivel de complejidad ascendente. Posteriormente, a la aplicación del CALS, se definió con las madres las prioridades de habilidades que los niños requerían desarrollar en el contexto del hogar.

El aporte de la familia en la definición de las destrezas por trabajar fue complementario al CALS. Sin este aporte, la propuesta no reflejaría las necesidades reales de la familia.

En el contexto de la investigación, los niños son los ejes de interés central; los apoyos de la familia y del equipo de profesionales, elementos que estimulan el desarrollo de su independencia. La figura 1 ejemplifica las relaciones.

Figura 1. Apoyos requeridos por los individuos con discapacidad para desarrollar la independencia.

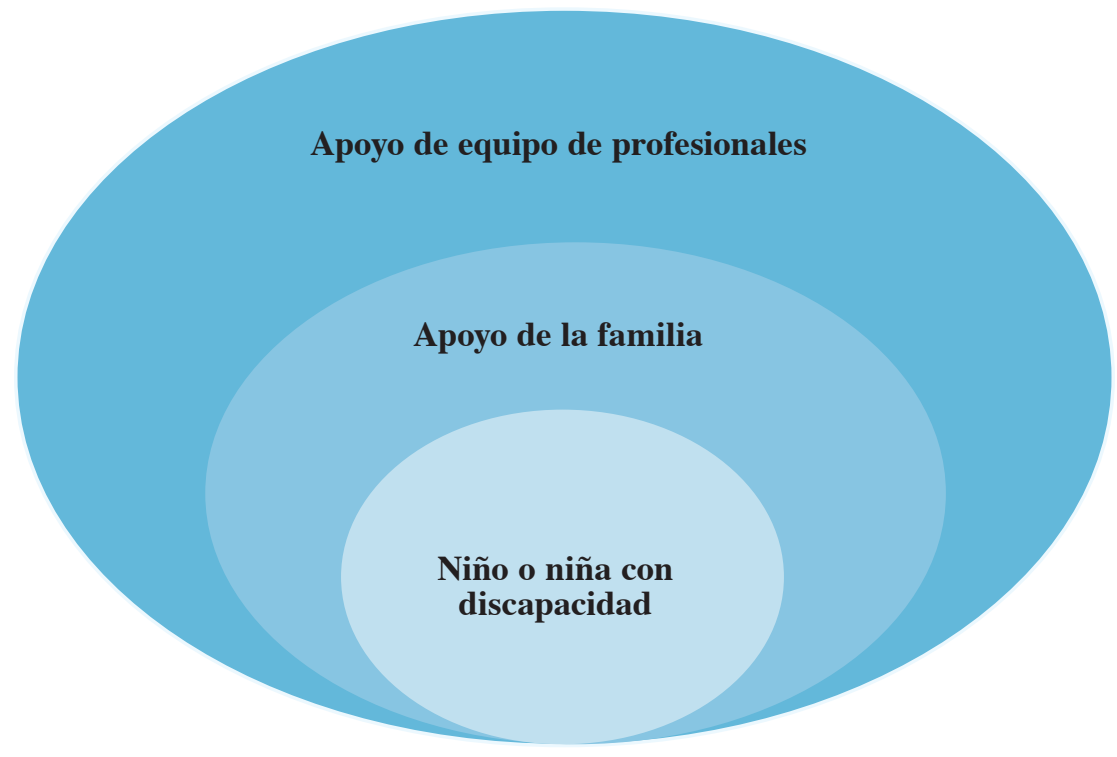

Nota. Elaborada por Rodríguez, A y Guerrero, C. (2011) 


\section{URL: http://www.una.ac.cr/educare}

El desarrollo de la independencia de la niñez está supeditado al apoyo y a las oportunidades que la familia le ofrezca. En algunos casos este proceso es natural, permitiéndole crecer con destrezas de independencia; sin embargo, en otros casos, la familia requiere el apoyo de profesionales que les ayuden a promover procesos de independencia a lo interno del hogar.

La propuesta conllevó la construcción conceptual de etapas que guiaron el proceso de construcción y reconstrucción de la misma, ajustada a las necesidades de las familias. La figura 2 ilustra este proceso.

Figura 2. Proceso de construcción y aplicación de la propuesta
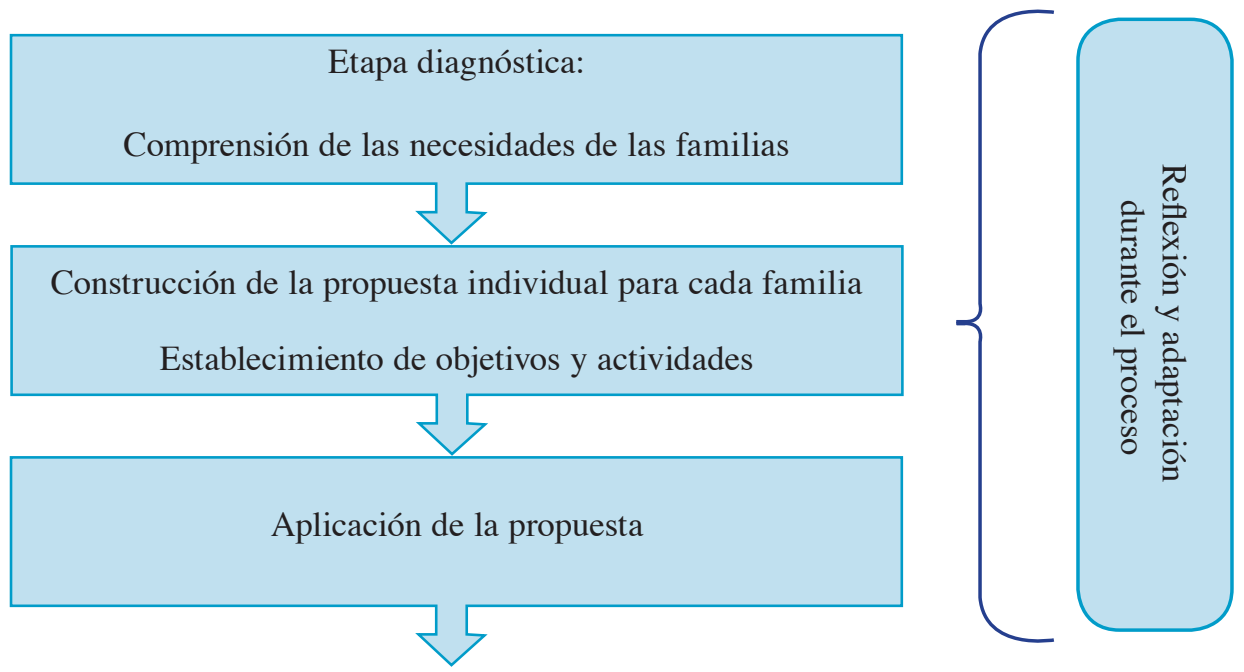

Nota. Elaborada por Rodríguez, A y Guerrero, C. (2011)

La propuesta pedagógica contemplaba un diagnóstico para comprender las necesidades de las familias. Posteriormente se desarrolló un plan individual adaptado a las necesidades de los niños y su entorno, estableciendo objetivos y actividades específicas dirigidas a alcanzar la independencia en el hogar. Las actividades fueron enriquecidas y reconstruidas en diversas sesiones por las familias participantes.

Con el fin de promover los procesos de reflexión y adaptación de la propuesta, las madres y una investigadora completaron un instrumento de autoevaluación en cada sesión de aplicación conjunta. El instrumento constaba de una serie de preguntas abiertas que permitían reflexionar e identificar aspectos importantes del proceso, tales como los sentimientos de los participantes al realizar las actividades, aspectos positivos y por mejorar encontrados durante cada una de las aplicaciones, así como recomendaciones para las aplicaciones de las siguientes sesiones.

Las visitas al hogar de la investigadora y los espacios de reflexión constituyeron una propuesta de apoyo para las familias. Más que guiar el proceso de los niños, les permitió a las familias identificar sus propias prácticas de sobreprotección hacia los menores, evidenciar los esfuerzos y 
los cambios en las actitudes que se debían realizar para asegurar el desarrollo de la independencia de los niños.

Las propuestas se organizan en la siguiente tabla, por familias y por destrezas. Es importante aclarar que los espacios en blanco en las columnas se deben a que los niños no necesitaban apoyo para desarrollar esas destrezas. Las destrezas corresponden a las diferentes áreas en las que está subdividido el CALS.

Tabla 1

Propuestas de trabajo para las familias I y II a raíz de los resultados del CALS y el aporte de las familias

\begin{tabular}{|c|c|c|c|}
\hline Tipo de destreza & Título del módulo & Objetivos para la familia I & Objetivos para la familia II \\
\hline \multirow{3}{*}{$\begin{array}{l}\text { Destrezas de vida } \\
\text { personal }\end{array}$} & Higiene y presencia & & $\begin{array}{l}\text { - Lavarse o bañarse } \\
\text { - Realizar diversas tareas relacionadas } \\
\text { con la higiene y presencia personal } \\
\text { - El cuido del cabello } \\
\text { - La higiene bucal y dental }\end{array}$ \\
\hline & Uso del servicio sanitario & $\begin{array}{l}\text { - Adquirir hábitos a la hora } \\
\text { de usar el servicio sanitario }\end{array}$ & $\begin{array}{l}\text { - Adquirir hábitos a la hora de usar el } \\
\text { servicio sanitario }\end{array}$ \\
\hline & Vestido & $\begin{array}{l}\text { - Quitarse prendas de vestir } \\
\text { - Ponerse prendas de vestir }\end{array}$ & $\begin{array}{l}\text { - Quitarse prendas de vestir } \\
\text { - Manipular cierres } \\
\text { - Ponerse prendas de vestir }\end{array}$ \\
\hline \multirow{3}{*}{$\begin{array}{l}\text { Destrezas de la vida en } \\
\text { el hogar }\end{array}$} & Cuidado de la ropa & $\begin{array}{l}\text { - Guardar la ropa de forma } \\
\text { adecuada }\end{array}$ & - Realizar tareas de limpieza de ropa \\
\hline & $\begin{array}{l}\text { Limpieza y organización del } \\
\text { hogar }\end{array}$ & $\begin{array}{l}\text { - Establecer hábitos } \\
\text { cotidianos/semanales }\end{array}$ & \\
\hline & Seguridad en el hogar & & $\begin{array}{l}\text { - Prevenir caídas y resbalones a causa de } \\
\text { obstáculos } \\
\text { - Manipular objetos afilados con las debidas } \\
\text { precauciones }\end{array}$ \\
\hline $\begin{array}{l}\text { Destrezas de la vida en } \\
\text { la comunidad }\end{array}$ & Interacción social & & - Desarrollar destrezas interpersonales \\
\hline $\begin{array}{l}\text { Destrezas de la vida en } \\
\text { la comunidad }\end{array}$ & Organización del tiempo & $\begin{array}{l}\text { Aplicar conceptos } \\
\text { generales de tiempo }\end{array}$ & \\
\hline Destrezas laborales & Relación con empleados & $\begin{array}{l}\text { - Relacionarse con los } \\
\text { compañeros de trabajo }\end{array}$ & \\
\hline
\end{tabular}




\section{Resultados de la propuesta}

Las características de cada núcleo familiar tiñen, con sus matices, el proceso de la aplicación de la propuesta y los resultados que se obtuvieron. En las siguientes dos secciones, se discuten los resultados obtenidos para cada una de las dos familias participantes.

\section{Familia 1}

Se evidencia que el niño 1 logró adquirir la mayoría de las destrezas de forma independiente, en especial las destrezas de vida en el hogar, seguida de las destrezas laborales. La cantidad de intentos realizados responde al número de ocasiones en que las madres promovieron en los niños realizar estas actividades y el número de intentos logrados corresponde al número de veces que el niño logró ejecutar lo solicitado de forma independiente. La tercera columna muestra los porcentajes obtenidos por el niño al promediar los intentos logrados y los intentos ejecutados.

La duración de la propuesta con esta familia duró aproximadamente dos meses, con visitas semanales o quincenales de la investigadora al hogar. Las visitas dependían del avance en las metas que las madres mencionaban haber adquirido con los niños entre sesiones. Durante la visita se le solicitaba al niño realizar las actividades en esa semana o quincena, además se recogían algunos videos que las madres habían tomado del niño durante la ejecución de las actividades y se hablaba con la madre sobre su proceso personal en la promoción de la independencia del niño.

Un elemento importante fue que, a través del proceso de acompañamiento en el hogar, este niño aprendió a cateteurizar su orina de forma independiente. Este fue un resultado que surgió de forma natural, ya que el uso del baño no fue incluido en la propuesta a petición de la madre. Inicialmente, se contempló en la propuesta el desarrollo de hábitos de higiene relacionados con el uso del baño, pero no el uso de este de forma directa, ya que según la madre, el niño no lograría hacer esto nunca de forma independiente.

Es importante reconocer que, en algunos ítemes, el número de intentos y de intentos logrados no varía significativamente. Esto puede deberse a que el niño presentaba la madurez necesaria para realizar los objetivos planteados, de tal forma que logró rápidamente desarrollar la habilidad esperada. Sin embargo, es pertinente reconocer que antes de la presentación de la propuesta este niño no realizaba ninguna de las acciones solicitadas de forma independiente, de ahí que el hecho de lograr realizarlas se considera un logro en sí mismo.

En relación al ítem de uso del tiempo, se puede evidenciar que aunque se trabajó de forma constante a través de las sesiones, el niño no logró interiorizar información relacionada a la organización del tiempo, por lo que este aspecto se considera como no logrado. No existe una comprensión del porqué no fue logrado: podría deberse a que el concepto de tiempo es abstracto a diferencia de las otras actividades que fueron más concretas o de ejecución. 
Tabla 2

Resultados de la propuesta en la familia $1_{-}$

\begin{tabular}{|c|c|c|c|c|c|}
\hline Módulo & Título & Objetivo a corto plazo & $\begin{array}{l}\text { Número de } \\
\text { intentos }\end{array}$ & $\begin{array}{l}\text { Número } \\
\text { de intentos } \\
\text { logrados }\end{array}$ & $\begin{array}{c}\% \\
\text { obtenido }\end{array}$ \\
\hline $\begin{array}{l}\text { Destrezas de } \\
\text { vida personal }\end{array}$ & Vestido & $\begin{array}{l}\text { Quitarse prendas con cintura } \\
\text { elástica }\end{array}$ & 19 & 16 & $84 \%$ \\
\hline $\begin{array}{l}\text { Destrezas de } \\
\text { vida personal }\end{array}$ & Vestido & $\begin{array}{l}\text { Ponerse prendas con cintura } \\
\text { elástica }\end{array}$ & 16 & 15 & $94 \%$ \\
\hline $\begin{array}{l}\text { Destrezas de } \\
\text { vida personal }\end{array}$ & Vestido & Ponerse calcetines & 22 & 14 & $63 \%$ \\
\hline $\begin{array}{l}\text { Destrezas de } \\
\text { vida personal }\end{array}$ & Vestido & $\begin{array}{l}\text { Ponerse y abrocharse calzado } \\
\text { provisto de tiras de velcro }\end{array}$ & 12 & 8 & $66 \%$ \\
\hline $\begin{array}{l}\text { Destrezas de } \\
\text { vida en el hogar }\end{array}$ & $\begin{array}{l}\text { Cuidado de la } \\
\text { ropa }\end{array}$ & $\begin{array}{l}\text { Poner la ropa sucia en una } \\
\text { cesta o cubo }\end{array}$ & 10 & 10 & $100 \%$ \\
\hline $\begin{array}{l}\text { Destrezas de } \\
\text { vida en el hogar }\end{array}$ & $\begin{array}{l}\text { Cuidado de la } \\
\text { ropa }\end{array}$ & $\begin{array}{l}\text { Diferenciar sus prendas de } \\
\text { entre las de los demás }\end{array}$ & 8 & 8 & $100 \%$ \\
\hline $\begin{array}{l}\text { Destrezas de } \\
\text { vida en el hogar }\end{array}$ & $\begin{array}{l}\text { Limpieza y } \\
\text { organización } \\
\text { del hogar }\end{array}$ & $\begin{array}{l}\text { Ordene su espacio en el } \\
\text { dormitorio }\end{array}$ & 13 & 13 & $100 \%$ \\
\hline $\begin{array}{l}\text { Destrezas de } \\
\text { vida en la } \\
\text { comunidad }\end{array}$ & $\begin{array}{l}\text { Organización } \\
\text { del tiempo }\end{array}$ & $\begin{array}{l}\text { Decir la edad } \\
\text { Mencionar los días que va a } \\
\text { la escuela }\end{array}$ & 24 & 0 & 0 \\
\hline $\begin{array}{l}\text { Destrezas de } \\
\text { vida en la } \\
\text { comunidad }\end{array}$ & $\begin{array}{l}\text { Organización } \\
\text { del tiempo }\end{array}$ & $\begin{array}{l}\text { Hacer referencia a la mañana, } \\
\text { mediodía, tarde y noche }\end{array}$ & 12 & 8 & $66 \%$ \\
\hline $\begin{array}{l}\text { Destrezas } \\
\text { laborales }\end{array}$ & $\begin{array}{l}\text { Relación con } \\
\text { empleados }\end{array}$ & $\begin{array}{l}\text { Pedir permiso para utilizar } \\
\text { material o instrumentos de } \\
\text { sus familiares y devolvelos en } \\
\text { buenas condiciones }\end{array}$ & 13 & 12 & $92 \%$ \\
\hline
\end{tabular}

\section{Familia 2}

La propuesta realizada en esta familia fue más extensa que la primera, debido a que lo patrones de sobreprotección estaban más arraigados en esta familia que en la primera, lo que ocasionó que el niño tuviera menos destrezas desarrollas para su edad que el niño de la primera familia. La duración en la ejecución, así como el apoyo requerido por la familia, fue mucho mayor.

En términos generales, esta familia necesitó el doble del tiempo para ejecutar las actividades. El proceso de acompañamiento fue similar al de la primera familia; sin embargo, las visitas fueron más constantes y el apoyo que la madre requería para sentir que ella podía promover destrezas de independencia en su hijo fue mayor. Un aspecto importante de mencionar fue que esta madre 


\section{URL: http://www.una.ac.cr/educare}

no comprendía completamente la discapacidad de su hijo, a pesar de que el niño asistía en ese momento a un centro de educación especial y que había tenido un seguimiento médico a través de los años. La madre mencionó que a través de esta experiencia tuvo el espacio para conversar sobre sus inquietudes y entender cuál es la condición de su hijo.

Aún con la necesidad de un apoyo más continuo, la familia fue capaz de desarrollar la propuesta con el niño. Un aspecto significativo de resaltar fue que el niño adquirió la mayoría de las destrezas de forma muy rápida. Es importante mencionar que al igual que el niño de la primera familia, este no realizaba ninguna de las actividades de forma independiente antes de iniciar el desarrollo de la propuesta.

Se estima que al igual que en la primera familia, este niño tenía cuatro años y presentaba la madurez necesaria para ejecutar las actividades de forma independiente, lo que carecía era de oportunidad para realizarlas sin ayuda de su familia, lo cual originó que las destrezas fueran adquiridas sin realizar muchos intentos.

De forma adicional a los objetivos de la propuesta, en el contexto del hogar surgieron oportunidades para desarrollar la independencia del niño. Por ejemplo, la familia mejoró la accesibilidad al baño para que el niño lograra utilizarlo por sí mismo. Adicionalmente, utilizaron unas resmas de hojas para hacer un banco para que se lavara las manos y había planes para construir pasamanos dentro de la casa con la intención de mejorar la movilidad del menor. Estos resultados son significativos, porque fueron construidos por las familias a raíz de las necesidades evidenciadas en el desarrollo de la propuesta.

Tabla 3

Resultados de la propuesta en la familia

\begin{tabular}{|c|c|c|c|c|c|}
\hline Módulo & Título & Objetivo a corto plazo & $\begin{array}{l}\text { Número de } \\
\text { intentos }\end{array}$ & $\begin{array}{l}\text { Número } \\
\text { de intentos } \\
\text { logrados }\end{array}$ & Resultados \\
\hline $\begin{array}{l}\text { Destrezas de } \\
\text { vida personal }\end{array}$ & $\begin{array}{l}\text { Higiene y } \\
\text { presencia }\end{array}$ & Lavarse y secarse la cara & 6 & 4 & $67 \%$ \\
\hline $\begin{array}{l}\text { Destrezas de } \\
\text { vida personal }\end{array}$ & $\begin{array}{l}\text { Higiene y } \\
\text { presencia }\end{array}$ & Peinarse o cepillarse el pelo & 6 & 4 & $67 \%$ \\
\hline $\begin{array}{l}\text { Destrezas de } \\
\text { vida personal }\end{array}$ & $\begin{array}{l}\text { Uso del } \\
\text { servicio } \\
\text { sanitario }\end{array}$ & $\begin{array}{l}\text { Bajarse o quitarse la ropa } \\
\text { antes de orinar o defecar }\end{array}$ & 13 & 13 & $100 \%$ \\
\hline $\begin{array}{l}\text { Destrezas de } \\
\text { vida personal }\end{array}$ & $\begin{array}{l}\text { Uso del } \\
\text { servicio } \\
\text { sanitario }\end{array}$ & $\begin{array}{l}\text { Abrocharse y colocarse la } \\
\text { ropa adecuadamente antes } \\
\text { de salir del cuarto de baño }\end{array}$ & 7 & 7 & $100 \%$ \\
\hline $\begin{array}{l}\text { Destrezas de } \\
\text { vida personal }\end{array}$ & $\begin{array}{l}\text { Higiene y } \\
\text { presencia }\end{array}$ & $\begin{array}{l}\text { Bañarse o ducharse } \\
\text { Hacer uso del baño sin tener } \\
\text { que pedir ayuda }\end{array}$ & 4 & 4 & $100 \%$ \\
\hline $\begin{array}{l}\text { Destrezas de } \\
\text { vida personal }\end{array}$ & $\begin{array}{l}\text { Higiene y } \\
\text { presencia }\end{array}$ & $\begin{array}{l}\text { Aplicarse perfume, agua de } \\
\text { colonia o loción en su ropa }\end{array}$ & 4 & 4 & $100 \%$ \\
\hline
\end{tabular}

Continúa... 
URL: http://www.una.ac.cr/educare

\begin{tabular}{|c|c|c|c|c|c|}
\hline Módulo & Título & Objetivo a corto plazo & $\begin{array}{l}\text { Número de } \\
\text { intentos }\end{array}$ & $\begin{array}{l}\text { Número } \\
\text { de intentos } \\
\text { logrados }\end{array}$ & Resultados \\
\hline $\begin{array}{l}\text { Destrezas de } \\
\text { vida personal }\end{array}$ & $\begin{array}{l}\text { Higiene y } \\
\text { presencia }\end{array}$ & Cepillarse los dientes & 8 & 8 & $100 \%$ \\
\hline $\begin{array}{l}\text { Destrezas de } \\
\text { Vida Personal }\end{array}$ & $\begin{array}{l}\text { Uso del } \\
\text { servicio } \\
\text { sanitario }\end{array}$ & $\begin{array}{l}\text { Situarse delante de la taza } \\
\text { del retrete para orinar } \\
\text { (varones) }\end{array}$ & 15 & 13 & $87 \%$ \\
\hline $\begin{array}{l}\text { Destrezas de } \\
\text { vida personal }\end{array}$ & Vestido & $\begin{array}{l}\text { Quitarse prendas que se } \\
\text { meten por la cabeza }\end{array}$ & 4 & 4 & $100 \%$ \\
\hline $\begin{array}{l}\text { Destrezas de } \\
\text { vida personal }\end{array}$ & $\begin{array}{l}\text { Higiene y } \\
\text { presencia }\end{array}$ & $\begin{array}{l}\text { Pedir ayuda cuando surgen } \\
\text { problemas en el cuarto de } \\
\text { baño }\end{array}$ & 4 & 4 & $100 \%$ \\
\hline $\begin{array}{l}\text { Destrezas de } \\
\text { vida personal }\end{array}$ & Vestido & Quitarse calcetines & 4 & 4 & $100 \%$ \\
\hline $\begin{array}{l}\text { Destrezas de } \\
\text { Vida Personal }\end{array}$ & Vestido & $\begin{array}{l}\text { Soltar los cierres de velcro } \\
\text { del calzado }\end{array}$ & 4 & 4 & $100 \%$ \\
\hline $\begin{array}{l}\text { Destrezas de } \\
\text { vida personal }\end{array}$ & Vestido & $\begin{array}{l}\text { Ponerse y quitarse calzado } \\
\text { sin cordones o hebillas }\end{array}$ & 4 & 4 & $100 \%$ \\
\hline $\begin{array}{l}\text { Destrezas de } \\
\text { vida personal }\end{array}$ & $\begin{array}{l}\text { Higiene y } \\
\text { presencia }\end{array}$ & Cambiarse de camisa & 4 & 4 & $100 \%$ \\
\hline $\begin{array}{l}\text { Destrezas de } \\
\text { vida en el hogar }\end{array}$ & $\begin{array}{l}\text { Cuidado de la } \\
\text { ropa }\end{array}$ & $\begin{array}{l}\text { Poner la ropa sucia en una } \\
\text { cesta o cubo }\end{array}$ & 4 & 4 & $100 \%$ \\
\hline $\begin{array}{l}\text { Destrezas de } \\
\text { vida en el hogar }\end{array}$ & $\begin{array}{l}\text { Cuidado de la } \\
\text { ropa }\end{array}$ & $\begin{array}{l}\text { Diferenciar sus prendas de } \\
\text { entre las demás }\end{array}$ & 4 & 4 & $100 \%$ \\
\hline $\begin{array}{l}\text { Destrezas de } \\
\text { vida en el hogar }\end{array}$ & $\begin{array}{l}\text { Cuidado de la } \\
\text { ropa }\end{array}$ & Guardar la ropa limpia & 4 & 4 & $100 \%$ \\
\hline $\begin{array}{l}\text { Destrezas de } \\
\text { vida en el } \\
\text { hogar }\end{array}$ & $\begin{array}{l}\text { Seguridad en } \\
\text { el hogar }\end{array}$ & $\begin{array}{l}\text { Meterse y salir de la bañera } \\
\text { o ducha }\end{array}$ & 4 & 4 & $100 \%$ \\
\hline $\begin{array}{l}\text { Destrezas de } \\
\text { vida en el } \\
\text { hogar }\end{array}$ & $\begin{array}{l}\text { Seguridad en } \\
\text { el hogar }\end{array}$ & Trasladar objetos frágiles & 4 & 4 & $100 \%$ \\
\hline $\begin{array}{l}\text { Destrezas de } \\
\text { vida en la } \\
\text { comunidad }\end{array}$ & $\begin{array}{l}\text { Interacción } \\
\text { social }\end{array}$ & $\begin{array}{l}\text { Expresar la ira } \\
\text { Hablar sobre sus estados de } \\
\text { ánimo }\end{array}$ & 8 & 8 & $100 \%$ \\
\hline
\end{tabular}




\section{Resultados del proceso de apoyo ofrecido a las familias}

Al analizar las auto-reflexiones familiares y al consultarles a ambas madres sobre el proceso vivido, los resultados alcanzados son positivos debido a que a través del apoyo brindado por las investigadoras se logró:

- Un proceso de comprensión sobre el nuevo "rol de madres", ya que este no está supeditado a las labores que ellas realizaban por sus hijos. Las madres debieron pasar por una comprensión de que ser una buena madre implica promover la independencia de sus hijos.

- Un compromiso hacia la realización de las propuestas y un proceso de reconstrucción de las mismas. Las madres implementaron, adaptaron y construyeron las actividades para que se adaptaran a la realidad del núcleo familiar. Este proceso de reconstrucción de las propuestas por parte de la familia es importante, porque garantiza la generación de futuros esfuerzos a lo interno del núcleo familiar.

- Un reconocimiento de que los niños y las niñas con discapacidad motora son personas con grandes habilidades y capacidades para emprender nuevos retos. Esta realización se evidencia en la expresión de una de las madres: "mi hijo es súper carga".

- Un proceso de crecimiento para los niños. Aunque fue difícil en algunos momentos comprender que la madre no iba a realizar las actividades acostumbradas por ellos, paulatinamente demandaron hacer las cosas por sí mismos, lo cual constituye un momento importante para el desarrollo de la independencia y la autoestima de estos individuos.

- La familia asume un rol de promotora del desarrollo de las habilidades adaptativas y de la independencia del niño con discapacidad motora. El cambio se dio como un proceso gradual de comprensión de las necesidades de los niños y de un reconocimiento de los patrones de crianza que no permitían que el niño desarrollara destrezas de independencia.

\section{Conclusiones}

La familia como primer formador del individuo incentiva o limita los procesos de crecimiento personal y social. Sin embargo, en las familias que participaron del estudio estos procesos de independencia se veían limitados por las visiones de discapacidad que prevalecían en el núcleo familiar. A pesar de que ambos niños tenían cuatro años, ninguno de los dos utilizaba el baño, ni se vestía de forma independiente o incluso ayudaba a acomodar sus juguetes en el hogar.

Las madres visualizaban su labor dentro de un paradigma asistencial, ya que velaban por el cuido del niño y los asistían en procesos que, de acuerdo con su edad, los niños podrían haber logrado de forma independiente. El apoyo brindado en la investigación moldeó la visión asistencial de las madres y les permitió, de forma gradual y a su ritmo, realizar modificaciones en las rutinas y solicitar a los niños realizar actividades de forma independiente. Para las madres, motivar e incentivar la independencia en los niños sin caer en conductas de sobreprotección aprendidas y utilizadas durante años simbolizó un reto personal.

Los resultados de este estudio son relevantes en cuanto muestran que cuando existe una guía para las familias de personas con discapacidad motora es más sencillo para estas iniciar procesos 
que de otra forma podrían verse pospuestos. Este resultado evidencia la necesidad de incentivar o crear propuestas de apoyo para las familias que les permitan construir sus propios procesos de crecimiento y el desarrollo de la independencia en sus niños con discapacidad motora.

Un elemento interesante fue que, a raíz de la aplicación de la propuesta, surgieron, de forma natural, nuevos procesos de apoyo y de independencia en el contexto familiar, los cuales fueron aprovechados por las madres para desarrollar nuevas habilidades en sus hijos. Por ejemplo, en uno de los casos el niño empezó a caminar sin ayuda después de iniciada la propuesta.

Finalmente, aunque este estudio se desarrolló en el contexto del hogar de ambos niños, es elemental reconocer el rol docente como un promotor de procesos de crecimiento de la niñez más allá del aula escolar. El personal docente puede convertirse en orientador de procesos de independencia en el hogar, construyendo con las familias de niños y niñas con discapacidad metas y acciones específicas de realizar tanto en el hogar como en el centro educativo. Para ello, requiere del apoyo de los padres y las madres, pero más allá de esto, se requiere que se mire al estudiante como un ser integral inmerso en un contexto familiar y social que no puede ser construido o impactado solamente desde el aula.

\section{Referencias}

Asociación Americana sobre Retardo Mental-AAMR. (2004). Retraso mental. Definición, clasificación y sistemas de apoyo. Madrid, España: Alianza Editorial.

Campabadal, M. (2007). El niño con discapacidad y su entorno (4 ${ }^{\mathrm{a}}$ reimpresión). San José, Costa Rica: EUNED.

Fontana, A., Alvarado, A. L., Angulo, M., Marín, E. y Quiroz, D. (julio-diciembre, 2009). El apoyo familiar en el proceso de integración educativa de estudiantes con necesidades educativas en condición de discapacidad._Revista Electrónic@ Educare, 13(2),17-35. Recuperado de http:// redalyc.uaemex.mx/redalyc/pdf/1941/194114401003.pdf

Fantova,F. (noviembre-diciembre, 2000). Trabajar con las familias de las personas con discapacidades. Siglo Cero, 31(192), 33-49.

Guía para la atención educativa a los alumnos y alumnas con discapacidad motora (s. f.) Andalucía, España: Consejería de Educación y Ciencia.

Peñafiel, F. (1998). Discapacidad motora: intervención psicopedagógica. En M. Á Lou y N. López (Coords.). Bases pedagógicas de la educación especial (pp. 235-252). España: Pirámide.

Póo, P. (2008). Parálisis cerebral infantil. Barcelona, España: Asociación Española de Pediatría.

Organización de las Naciones Unidas [ONU]. (2006). Convención sobre los derechos de las personas con discapacidad. Nueva York. Estados Unidos. 